\title{
'Diz-me como ages, dir-te-ei quem és': João Couto e a génese do Museu -Biblioteca Condes de Castro de Guimarães, em Cascais
}

\author{
Maria Mota Almeida ${ }^{1}$
}

\section{Resumo:}

Este artigo baseia-se, parcialmente, na investigação elaborada no âmbito da Tese de Doutoramento em Museologia. Centra-se no 'estudo de caso' de um processo museológico de raiz local: o Museu - Biblioteca Condes de Castro Guimarães, única instituição museal no concelho de Cascais durante meio século.

Tendo como base epistemológica o campo de investigação da Sociomuseologia, partindo de fontes primárias, secundárias e de bibliografia complementar, procurou-se apreender a forma como o primeiro responsável desta instituição pensou, percebeu e construiu, na sua génese, a função museológica.

A pesquisa orientou-se numa dupla vertente: por um lado, estudou-se, mediante a metodologia de análise de conteúdo, o pensamento e a ação do conservador João Couto; por outro, procedeu-se ao historial do museu, dos anos 30 aos anos 40 do século XX, o que permitiu compreender que, desde muito cedo, a função social e educativa esteve presente através de uma proposta que se foi construindo ao longo das décadas.

Demonstrou-se a relevância do contributo do conservador para a construção de uma instituição cultural mais próxima da comunidade, destacando o pioneirismo das práticas de cariz social, cultural e educativo que, posteriormente, se refletiu no desenvolvimento do seu trabalho no Museu Nacional de Arte Antiga, em Lisboa.

${ }^{1}$ Investigadora integrada do Instituto de História Contemporânea da FCSH-UNL, Doutoramento em Museologia pela ULHT, Docente na Escola Superior de Hotelaria e Turismo do Estoril (ESHTE) 
Palavras - Chave: Museologia; Sociomuseologia; Educação; Museus Locais; Comunidade

Abstract:

This paper summarizes part of the research developed under the Doctoral Thesis in Museology. It focuses on the 'case study' of a local root museum process: Museu - Biblioteca Condes de Castro Guimarães, the sole institution museum in Cascais for half a century.

Based on the epistemological field on Socio-museology research, upon primary sources, secondary and complementary bibliography, we tried to comprehend how the main founders of this institution thought, perceived and established the museological function at its origins.

The research was developed in two complementary orientations: on one hand we studied the thoughts and actions of the museum curator João Couto through the content analysis methodology of their scholarly previously published texts. In parallel, we studied the history of the museum starting from the 1930s until the 1940s. This allowed us to perceive that, very early, the social and educational functions were present and continued to be developed over the decades that followed.

We demonstrate the relevance of the curator's work in the the construction of a cultural institution, engaging in social, cultural, and educational pioneering practices to benefit the community, and that we believe influenced the work of Museu Nacional de Arte Antiga, in Lisbon.

Key-words: Museology; Socio-museology; Education; Local Museums; Community.

\section{Introdução}

O presente artigo centra-se no 'estudo de caso' de um processo museológico de raiz local: o Museu - Biblioteca Condes de Castro Guimarães, única instituição museal no concelho de Cascais durante meio século, e baseia-se parcialmente na investigação elaborada no âmbito da Tese de Doutoramento em Museologia.

Tendo como base epistemológica o campo de investigação da Sociomuseologia, partindo de fontes primárias, secundárias e de bibliografia complementar, 
procurou-se apreender a forma como o primeiro responsável por esta instituição pensou, percebeu e construiu, na sua génese, a função museológica.

Demonstrou-se a relevância do seu contributo para a construção de uma instituição cultural mais próxima da comunidade, destacando o pioneirismo das práticas de cariz social, cultural e educativo aqui implementadas.

Os estudos introdutórios a que se procedeu permitiram constatar que as instituições museais têm sido estudadas sobre diferentes prismas: tipos / modelos de museus, história das coleções, atividades, etc., mas, frequentemente, as pessoas responsáveis pelos mesmos, que contribuíram, não apenas para a salvaguarda do património que Ihes foi confiado mas que, pelas opções tomadas, foram responsáveis por criar organismos, mais ou menos interventivos na comunidade, defendendo muitas vezes ideias diferentes das veiculadas pelo poder instituído, são votadas ao esquecimento.

Deste modo, consideramos que a temática explorada é relevante para a construção do conhecimento a nível do património local e dos protagonistas de uma nova forma de pensar e fazer museal, contribuindo decisivamente para a interação entre cultura e sociedade. Pensamos que servirá de reflexão, na contemporaneidade, pela qualidade do vanguardismo do pensamento e ação que João Couto imprimiu neste espaço e que transporta uma responsabilidade acrescida, não só para a instituição objeto de estudo, mas para o conhecimento do pensamento museológico interligado com o processo pedagógico. João Couto irá, logo em seguida, trabalhar no Museu Nacional de Arte Antiga, onde implementará muitas destas ideias e fará sempre uma ligação entre este Museu Nacional e o Museu de Cascais.

\section{Problemática}


Assim, o presente estudo pretende verificar que concepção ou concepções museais marcaram os primeiros anos de vida deste museu, contribuindo para a construção da sua identidade. Definiu-se a seguinte questão inicial:

- de que forma o primeiro Conservador do Museu-Biblioteca Condes de Castro Guimarães pensou, percebeu e construiu, na sua génese, a função museológica?

O arco temporal estabelecido - 1930 - 1941 corresponde, grosso modo, à primeira década de vida deste Museu - Biblioteca, único museu no concelho de Cascais até à década de 80. Apesar de João Couto só ter sido conservador entre 1930 e 1932, os anos 30 marcam o início de uma época de colaboração regular com o mesmo, que, com algumas intermitências, se mantém até ao seu óbito em 1968. Foi, como já mencionado, o seu primeiro Conservador (1930-32), mantém-se como Conservador Honorário a partir de 1934, assumindo, em colaboração com José de Figueiredo, a atividade cultural do Museu. Entre 1938 - 41 vai assumir a função de Vogal Cultural da Comissão Administrativa. Na década de 60 acompanha, com muito entusiasmo, a formação das monitoras, a criação e atividade dos Serviços Educativos, fundados por Maria Alice Beaumont, neste Museu Biblioteca, à semelhança dos Serviços Educativos por si criados no Museu Nacional de Arte Antiga.

O trabalho partiu de um grupo de hipóteses que foram definidas da seguinte forma:

- O discurso ideológico e as práticas museais do primeiro responsável do museu - biblioteca evidenciam a função museológica numa perspectiva elitista, reproduzindo os valores ideológicos do seu tempo.

- O discurso ideológico e as práticas museais do primeiro responsável do museu - biblioteca 
apresentam a função museológica numa perspectiva de integração social.

- O discurso ideológico e as práticas museais evidenciadas pelo responsável do museu - biblioteca patenteiam a função museológica como uma ação educativa.

- A tipologia de museu definiu o perfil das ações sócio-culturais e educativas deste museu.

- Entre os anos 30 e 40 alguns princípios adoptados pela Sociomuseologia já estavam presentes na reflexão - ação deste museu biblioteca.

Para estas hipóteses, cujo objectivo primordial é aferir pensamento / doutrina e ação na génese do museu e que, ao admitir "a presença da gota de sangue no museu significava também aceitá-lo como arena, como espaço de conflito e luta, como campo de tradição e contradição" (Chagas, 2003, p.21), concebeu-se um corpo de múltiplas interrogações que se tentaram equacionar ao longo deste trabalho. Assim, e perante as hipóteses delineadas, o processo investigativo foi desenvolvido, igualmente, com a finalidade de responder às seguintes questões:

- É a tipologia do museu que define o pensamento museológico, ou são as concepções defendidas pelos profissionais que aí operam?

- É a tipologia de museu que define o perfil das ações sócio-culturais e educativas dos museus, ou são as concepções de museu, de museologia e de educação defendidas pelos profissionais?

- Qual a importância da atuação de João Couto para a evolução do pensamento museológico e para o processo pedagógico?

Deste modo, o trabalho acompanhará os primeiros anos de existência do museu - biblioteca, numa dupla 
vertente: por um lado, destacando o pensamento e a ação de João Couto, mediante a análise de conteúdo a que foram submetidos os seus textos doutrinais; por outro, proceder ao historial do museu, partindo de bibliografia e fontes diversas, trabalhadas de modo a haver uma perspectiva diacrónica do labor aí realizado, numa comunhão que se almeja permanente, entre a reflexão museológica e a reflexão sobre a prática museológica. Pretende-se compreender como é que aquela personalidade conferiu ao museu a sua dimensão especificamente humana, como percebeu, pensou e praticou a museologia na sua relação com a educação.

\section{Metodologia de Investigação}

A investigação empreendida é um 'estudo de caso', porque não se pode exercer controlo sobre os acontecimentos e possibilita o aprofundamento de uma temática local, juntamente com questões teóricas ligadas à museologia. Os dados recolhidos, operacionalizar-se-ão mediante o levantamento e tratamento de fontes primárias e secundárias, permitindo, o resultado deste trabalho, extrair ligações entre variáveis e fazer a verificação das hipóteses enunciadas. Não se cingiu a um único método de recolha de informações, mas recorreu-se a estratégias compostas (Ketele, 1999, p. 38) quer para preparar a recolha de dados quer para a completar.

A preocupação, em perceber melhor as doutrinas do pioneiro deste museu, conduziu, para além de outros documentos, alguns dos quais fontes primárias, ao levantamento exaustivo e posterior leitura de um conjunto de artigos, escritos por João Couto, maioritariamente insertos em publicações periódicas que, após uma leitura impressiva, se considerou fundamentais para perceber o seu pensamento doutrinal relativamente à função que uma instituição cultural, neste caso o Museu - Biblioteca, devia desempenhar. Pelas 
suas características, este 'corpus' documental tornou-se imprescindível para o estudo doutrinal da génese do Museu Biblioteca Condes de Castro Guimarães, não só porque espelha o pensamento do conservador, como legitima, com fundamentação consistente e refletida, as práticas por ele implementadas, algumas das quais inovadoras no nosso país.

A natureza deste material empírico, e de acordo com os vectores da problemática enunciada, conduziu, numa primeira fase, à "leitura flutuante" (Bardin, 1988, p. 96), que permitiu articular os procedimentos abertos e fechados e fazer uma primeira inferência sobre a validade dos conceitos previamente definidos. Esta leitura impressiva necessitava de ser sustentada pela utilização de análises de conteúdo categoriais e temáticas aplicadas ao conteúdo dos textos doutrinais, com resultados de tipo qualitativo. Procurou-se ler exaustivamente os textos para não perder a sua "realidade" empírica e factual, sem esquecer o princípio de que a teoria comanda a pesquisa, evitando a desestruturação opinativa e impressiva. O plano de trabalho para a análise de conteúdo foi elaborado com base no modelo de análise categorial e temática apresentada por Bardin (1988). A análise de conteúdo é um instrumento "polimorfo e polifuncional" (Bardin, 1988, p. 9), isto é, um instrumento com formas várias e adaptáveis, com técnicas múltiplas e multiplicadas, que contribui para a "ultrapassagem da incerteza" e para o "enriquecimento da leitura" (Bardin, 1988, p. 29), através da "desocultação" (Bardin, 1988, p. 9) do não dito, tornando-nos quase detectives textuais, procurando perceber os sentidos e os significados do discurso.

\section{Percurso biográfico de João Rodrigues da Silva}

\section{Couto}

João Couto nasceu em Coimbra, no ano de 1892, falecendo na Capital, em 1968. Obteve o bacharelato em

Direito e licenciou-se em Histórico-Geográficas e 
Filosóficas. Nesta época foi aluno de António Garcia Ribeiro

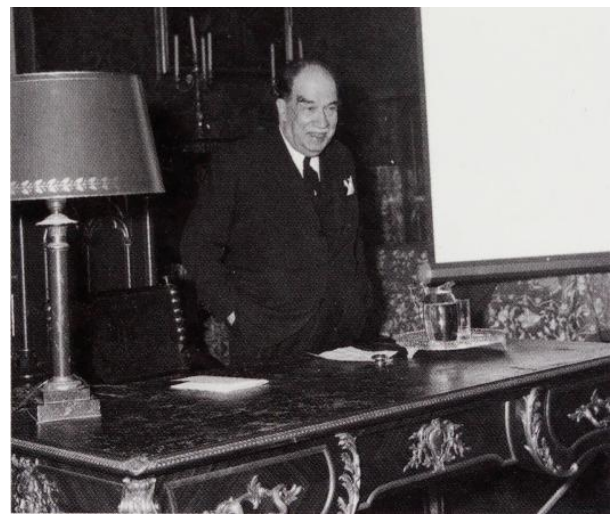

Figura 1 João Rodrigues da Silva Couto no M-BCCG - 1930 Fonte: Carvalho, A. (Coord.). (2008). Museu- Biblioteca Condes de Castro Guimarães - Roteiro, p.20

de Vasconcelos e Eugénio de Castro, frequentadores das tertúlias culturais que seu tio, Rodrigues da Silva, promovia na farmácia de que era proprietário e que o jovem Couto frequentava com alguma assiduidade.

Com Carolina Michaelis de Vasconcelos e seu marido Joaquim de Vasconcelos, prepara e empreende visitas guiadas ao património da região para que os seus alunos conheçam o meio em que vivem. Defensor, desde muito cedo, da 'educação pela arte', apela, igualmente, para a indispensabilidade da componente prática desta disciplina, exercitada dentro e fora do espaço escolar, em contato com o património, nomeadamente com os museus.

As ideias acima enunciadas vão ser postas em prática, nos anos subsequentes, porquanto João Couto vai ser professor do Liceu Normal D. João III, da Escola Brotero ambas em Coimbra - e, em simultâneo, conservador tirocinante no Museu Machado de Castro até 1924. Nesta instituição o contato com António Augusto Gonçalves, republicano histórico e referente ético de gerações 
republicanas, como por exemplo António José de Almeida, abre-lhe as perspectivas para o aproveitamento das possibilidades educativas do museu.

Desde muito cedo, manifestou uma sensibilidade para as ideias anglo-saxónicas, materializada em 1914, através de um estágio, embora breve, na National Gallery (Couto, 1965, p.3) e no Victoria \& Albert Museum que, ao coincidir com o início da Grande Guerra, o obriga a voltar a Portugal. Porém, a apetência pelo mundo dos museus não se extingue com este precipitado regresso e, longe de se confinar às estreitas fronteiras nacionais, galga o Atlântico procurando novidades. O contato com a bibliografia norte-americana, sobretudo através dos Boletins existentes no Museu Nacional de Arte Antiga, conseguidos por permuta (Cf. Couto, 1961, p.48), é tão intenso e inspirador que, quando no final da década de 20, organiza e coordena o primeiro 'Serviço de extensão escolar' do Museu Nacional de Arte Antiga, segue de muito perto o programa do Metropolitan Museum de Nova York.

Em 1924 desloca-se para Lisboa, pedindo transferência para o Liceu Pedro Nunes, pois havia sido convidado por José de Figueiredo, para o Museu Nacional de Arte Antiga, como conservador tirocinante (1924-28). Concilia pedagogicamente estas duas ocupações, começando a estabelecer uma relação próxima entre os seus alunos e o museu onde trabalha, a título não remunerado, implementando, na prática, o que sempre defendeu: a educação integral através e em contato direto com as obras de arte. Entre 1928-30 torna-se conservador adjunto do Museu Nacional de Arte Antiga, criando o primeiro 'Serviço de extensão escolar', seguindo de perto o modelo norteamericano, como mencionado anteriormente. No sentido de atingir os objetivos que se propunha, diversifica atividades onde inclui projeção de filmes, palestras, visitas, cursos e conferências, e informa periodicamente as escolas de Lisboa sobre as ações que o museu propõe. 
A abertura de concurso para Conservador do MuseuBiblioteca Condes de Castro Guimarães, o empenhamento demonstrado e o facto de José de Figueiredo fazer parte da Comissão Administrativa do mesmo, são motivos mais que suficientes para se candidatar. É selecionado e inicia um trabalho que vai modelar irreversivelmente aquele espaço, como iremos explanar.

Em 1932, João Couto regressa ao Museu Nacional de Arte Antiga onde, após a morte de José de Figueiredo, assume a função de diretor, cargo que exercerá com generosa dedicação entre 1938 e 1962. Neste cargo põe em prática o que, ajudado pela sua propensão para abarcar influências internacionais, pensa dever ser um museu moderno. Organiza, em 1953, o 'Centro Infantil', cuja responsabilidade direta delega na pintora Madalena Cabral e que irá influenciar a criação, na década de 60, dos Serviços Educativos de vários museus: Museu Soares dos Reis - Porto -, Museu de Aveiro, Museu Grão Vasco -Viseu -, Museu - Biblioteca Condes de Castro Guimarães - Cascais -, Museu da Fundação Calouste Gulbenkian - Lisboa - e que, com terminologia diversa, 'Serviço Infantil', 'Serviço Educativo' e 'Serviço de Educação', inspirou várias gerações, estando na base da constituição de outros serviços educativos.

\section{Discursos de João Couto}

\section{pela educação}

\subsection{A concepção de educação: a regeneração social}

Ao fazer a análise de conteúdo relativa à função da Educação, nas narrativas de João Couto, conclui-se que o Conservador, cuja primeira ocupação foi a docência, foi um cidadão empenhado na intervenção cívica e educativo pedagógica, e cujas ideias e ideais se vão refletir na prática quotidiana, apesar da sua opinião poder colidir com teorias emanadas pelo poder instituído. Podemos identificar um 
núcleo dicotómico agregador a partir do qual explana todas as suas ideias sobre o ato de educar:

- a educação ativa - inovadora /moderna; versus

- a educação passiva - tradicional / a que está em vigor na época em que escreve;

Esta dicotomia torna-se determinante para a estruturação das suas ideias. A caracterização, do que entende ser a educação ativa, é sempre acompanhada por um núcleo global e associado de características que podemos agrupar do seguinte modo:

- Uma concepção de escola encarada como instituição viva;

- A importância do estudo da arte em qualquer grau de ensino;

tudo configurado num quadro justificativo do processo de aprendizagem centrado na formação integral do ser humano. Formação esta, alicerçada na responsabilização das instituições culturais em todo o processo, bem como do indivíduo enquanto sujeito da sua própria educação, como facilmente se verifica no quadro infra.

$\mathrm{Na}$ opinião por si veiculada ao longo dos textos, a escola deve ser: viva, acessível, motivadora, com uma enorme valorização do ensino informal e experimental nomeadamente na área das ciências e das artes - sem aparato livresco, com a utilização de instrumentos que facilitem a compreensão e aproximem os educandos da observação dos temas a trabalhar. Ao nível das metodologias, destaca a necessidade de aliar a teoria à prática, promovendo o ensino da arte em contacto com as obras, ou de uma forma indireta: mediante a intensiva utilização do epidiascópio, projeções luminosas de filmes ou diapositivos, quadros parietais; ou de uma forma direta: valorizando a saída para o exterior, 
mediante excursões que permitam conhecer o património local. Estas visitas, fundamentais em qualquer grau de ensino,

\section{Quadro 1 A escola ativa - João Couto}

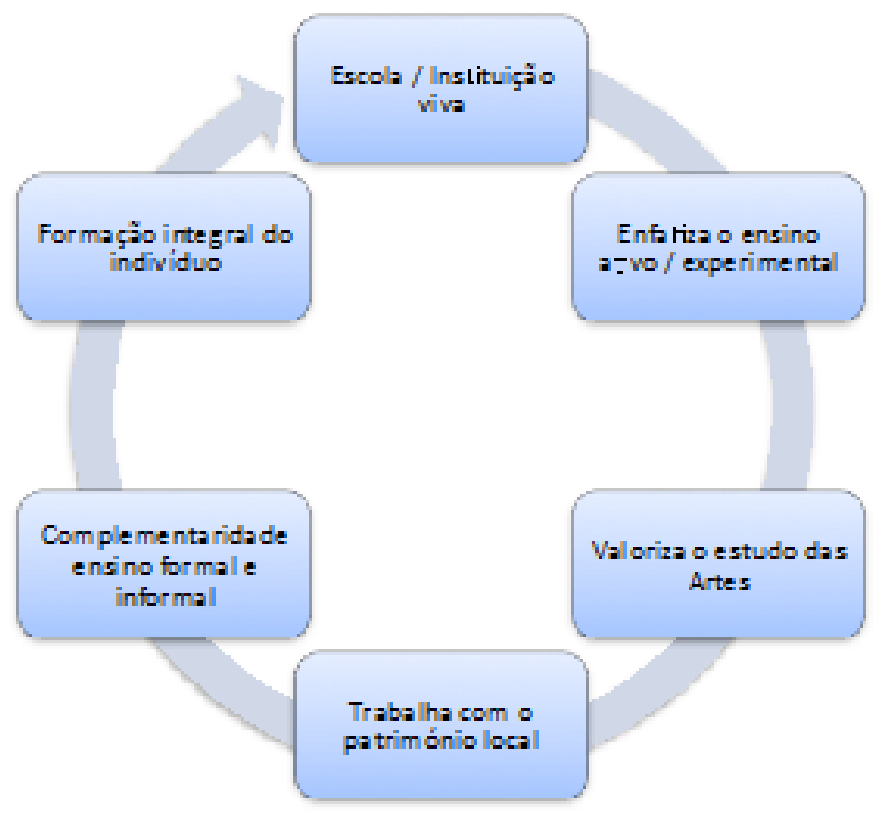

Elaboração própria, 2012.

podem e devem ser feitas aos monumentos, museus, ateliers dos artistas, exposições de arte.

Há, ao longo dos textos analisados, uma clara valorização da componente prática que associa o prazer à aprendizagem, apelando ao desenvolvimento da curiosidade, imaginação, interesse, recreação, compreensão, criatividade, desenvolvimento do espírito crítico, para formar pessoas responsáveis, críticas e com uma capacidade de intervenção esclarecida e autónoma. Tal como propagaram os republicanos quando advogavam que o grande objetivo do 
Estado deveria ser o da instrução, enquanto aprendizagem aliada à felicidade, contribuindo para a formação integral dos indivíduos e para a construção do 'Homem Novo'.

Por sua vez, a educação passiva aparece sempre agregada a um núcleo coerente e associado de características, tais como: carga horária excessiva, conteúdos extensos, ensino árido, magistral, acrítico, dogmático - com discurso padronizado -, asfixiante, pela ausência de educação estética e artística: "nos livros / manuais, nas diretivas pedagógicas, no edifício escolar, no ensino" (Couto, 1932, p. 317). Assistese, complementarmente, à ausência de atividades extra escolares, que anulam o prazer que deve acompanhar o ato de conhecer. A ausência de componente prática, pela falta de aulas no exterior do espaço escolar e pela inexistência de análise das obras de arte, conduz à desvalorização das outras instituições culturais na formação do cidadão, nomeadamente do museu.

No quadro infra podemos ver, esquematicamente, a forma como, em seu entender, se devia fazer a articulação entre a escola e o museu, evitando que este repetisse o modelo da escola, mas que se constituísse como uma alternativa complementar, numa tentativa equilibrada de contribuir para a formação holística do ser humano:

As práticas existentes, por si metódica e vigorosamente contrariadas, legitimam o valor, que se pretende indiscutível, da Educação do Estado Novo, e o desinvestimento, não assumido, no ensino, em que a instrução, se todos souberem ler e escrever, é automaticamente desvalorizada - como defendia Oliveira Salazar em 1935 -, devendo confinar-se a uma elite.

Sendo a instrução e a educação, na óptica de Couto, essenciais para a elevação moral e espiritual de todos, ideia sobejamente repetida ao longo dos vários textos analisados, defende que outras instituições culturais, para além da escola, devem contribuir para atingir plenamente esse objetivo, de 
onde se destaca a instituição museu, nomeadamente o Museu - Biblioteca Condes de Castro Guimarães.

Quadro 2 Articulação 'escola-museu' e 'museu-escola' - João Couto

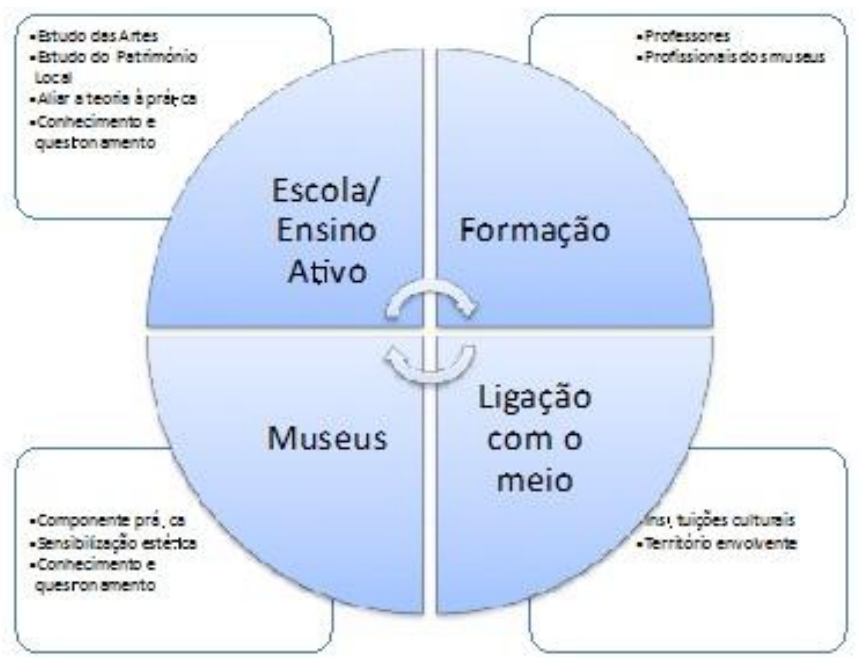

Elaboração própria, 2012.

Aliando o 'museu à escola' e a 'escola ao museu', estava a contribuir para consubstanciar a confiança republicana no poder transformador da educação e na construção de uma sociedade em que os indivíduos exercessem esclarecidamente o seu dever de cidadania, pelo reforço da educação cívica.

4.2 A concepção de museu: "instrumento essencial de cultura e de educação"

Após a análise de conteúdo, verificámos que a sua concepção de museu nos é transmitida através de uma dicotomia, opondo neste caso os: 
- Museus Modernos - cujo objetivo é ajudar a formar o indivíduo numa perspetiva de educação integral;

versus

- Museus Tradicionais - cujo objetivo é trabalhar para e com o objecto;

Esta dicotomia torna-se, mais uma vez, determinante para a estruturação das ideias por si defendidas. Verifica-se que João Couto não identifica apenas a sua visão de museu, constrói-a através de uma realidade que pretende demonstrar, assumindo uma tomada de posição, bastante determinada e incisiva, no campo museal. Mais uma vez se afasta de um discurso puramente teórico para, não só propor medidas concretas, mas que, de forma atuante, vai concretizar ao longo da sua carreira, quer no MuseuBiblioteca Condes de Castro Guimarães, como veremos mais adiante, quer no Museu Nacional de Arte Antiga, influenciando várias gerações de profissionais de museus.

A caracterização dos Museus Modernos configura-se, deste modo, num quadro de quatro categorias interpretativas:

dinâmica;

- definição de Museu - instituição viva e

- função do Museu numa dupla vertente:

o enquanto instituição que complementa a escola, mas que se abre a outros níveis etários, numa clara aproximação à comunidade;

o como elemento formador / transformador do indivíduo;

- formação dos funcionários dos museus (necessidade de preparação específica);

- Influência teórico - prática internacional em termos de museologia ativa; tudo enformado num quadro justificativo da função 
social do museu, baseada na função educativa, essencial para a formação integral do sujeito.

A explanação aparece sempre agregada a um núcleo coerente e associado de características, como seja: o museu como uma instituição viva, atuante, interventiva, trabalhando para e com o público, procurando, ao complementar o ensino, ajudar a formar o indivíduo numa perspetiva de educação holística, como se pode ver no quadro seguinte:

\section{Quadro 3 Museus modernos - João Couto}

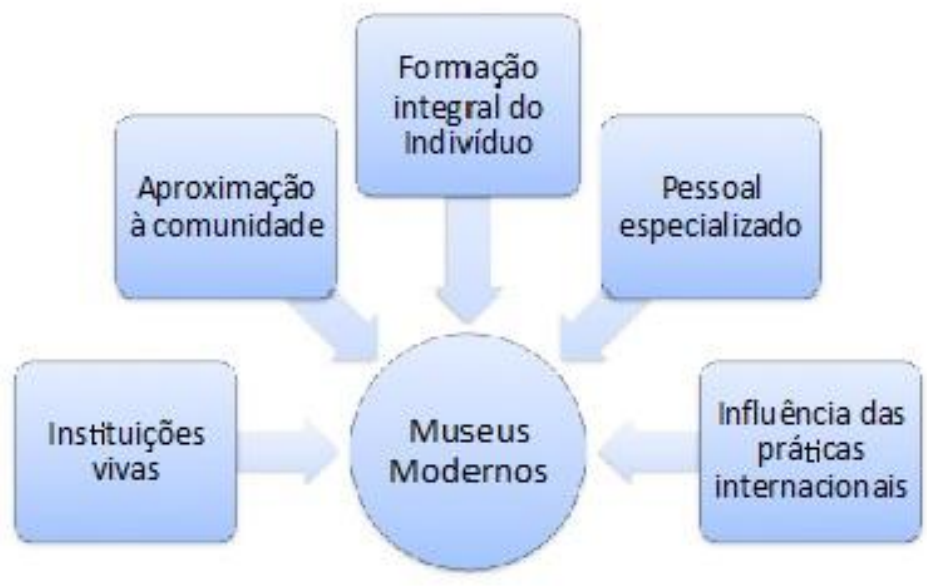

Elaboração própria, 2012.

O museu é caracterizado numa dupla perspetiva que se entrelaça no trabalho quotidiano da instituição: por um lado, é um lugar de preservação da memória, evitando a 'fuga' de testemunhos do homem; por outro, é considerado "o abrigo onde cabem todas as manifestações artísticas" (Couto, 1931/71, p. 13), não se limitando aos objetos tradicionalmente considerados artísticos. Neste sentido, deve despertar curiosidade e desenvolver o espírito crítico, 
pugnando por um ensino vivo e aliciante, servindo como complemento do ensino e extensão ativa e dinâmica das escolas, onde verdadeiramente se deve ensinar/ aprender a arte, a estética e a ciência, mediante uma multiplicidade de atividades: palestras, palestras ilustradas, projeções, filmes, exposições temporárias, visitas guiadas e contacto com artistas vivos. Estas atividades permitem desenvolver a capacidade de conhecer acontecimentos históricos, a evolução científica e social e as etapas da História da Arte, bem como apreciar e comparar outras épocas e outros países. Mais uma vez podemos estabelecer um paralelo com o que se passava nos museus da América do Norte, onde a sensibilidade crescente para a valorização da acessibilidade museal, mediada pela ação educativa, conduziu à diversificação de estratégias compostas por ações muito diferenciadas. Estas ideias inovadoras vão ser disseminadas mediante bibliografia especializada e, igualmente, através de seminários, congressos e reuniões.

$\mathrm{Na}$ base de todo este trabalho de democratização do acesso à cultura há, como mencionámos, um claro predomínio da função educativa, na perspetiva de uma aprendizagem ao longo da vida que, para ser eficaz, exige um programa educativo bem estruturado, eficiente, e espaços próprios, destinados a esse fim, onde se aprende e colabora, desenvolvendo a autonomia na aprendizagem.

Encontramo-nos, deste modo, perante a concepção de museu, muito relacionada com a concepção de escola e de educação que deve abrir as portas à comunidade, com o objetivo primordial de se tornar formador / transformador do indivíduo, pela sua valorização. Desperta as emoções, a curiosidade, a imaginação, a sensibilidade, o sentido artístico, e fortifica o espírito, tornando-se um 'tónico' e um calmante essencial para o equilíbrio de toda a comunidade.

O museu, entendido como o complemento da formação, instrução/ educação familiar e escolar, não é 
apenas um elemento de valorização sociocultural, mas um elemento de construção dinâmica de cidadania. Contribui tanto para a formação do gosto, como do carácter e da sensibilidade, ao despertar o interesse pela beleza e a curiosidade pela arte, ao fomentar a capacidade de criação artística, ao criar hábitos de frequentar galerias, apreciar e estimar a arte, como para a formação moral, espiritual e ética, ao desenvolver, por exemplo, a estima e o sentido de preservação patrimonial.

As instituições, que 'viviam orgulhosamente sós', são consideradas por si como museus tradicionais, como instituições mortas, como podemos ver no quadro infra:

\section{Quadro 4 Museus tradicionais - João Couto}

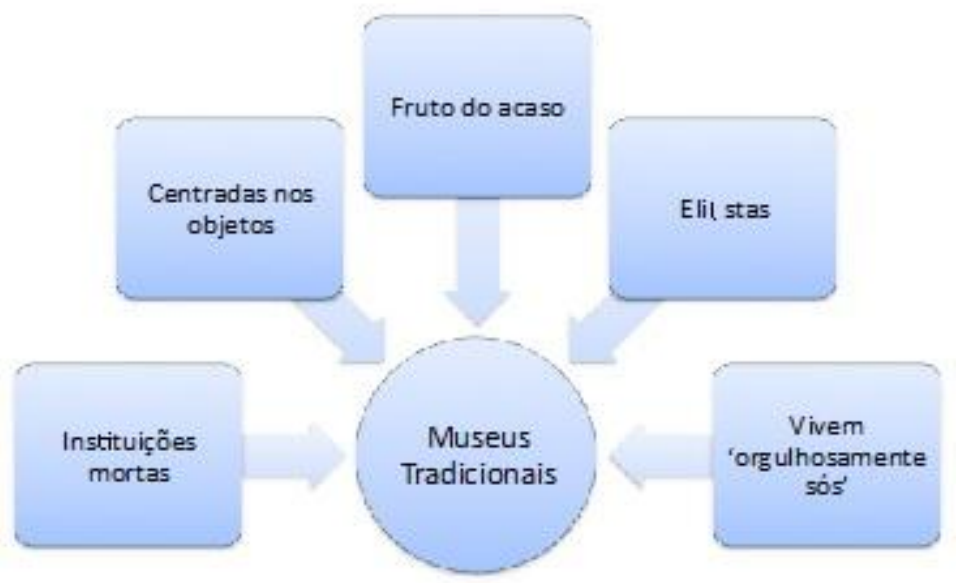

Elaboração própria, 2012.

Nos textos que escreveu, a caracterização dos museus tradicionais aparece sempre agregada a um núcleo coerente e associado de características, tais como: depósitos, arrecadações, túmulos, armazéns, locais de acumulação e apresentação de objetos, ausência de função cultural, 
elitismo, que João Couto associa aos museus europeus onde "a maior parte, se não a totalidade das galerias são apenas opulentas arrecadações" (Couto, 1932, p. 321). É evidente que elas cumprem uma função importante, "porque salvam e conservam as obras de arte, que, sem elas se perderiam, mas não desempenham o papel educativo imposto pelas necessidades e pelas despezas que acarretam" (Couto, 1932, p.321). A conservação patrimonial não pode ser considerada um fim mas apenas como um recurso que, mediado pela função educativa, contribui para a transformação do indivíduo. Vejamos de seguida como estas ideias foram implementadas no Museu de Cascais, na década de 30.

\section{Museu- Biblioteca Condes de Castro Guimarães}

5.1 Década de 30 - tempos de formação : alargamento de públicos / aproximação à comunidade.

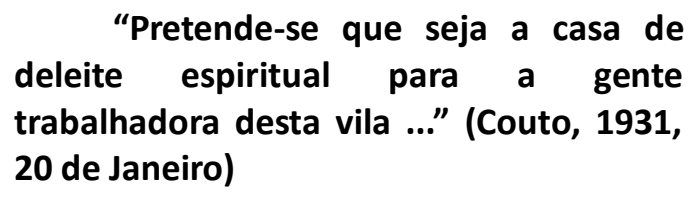

Manuel de Castro Guimarães doa, à Câmara Municipal de Cascais, o seu palacete, para que se constituísse um Museu Municipal e uma Biblioteca Pública. João Couto, logo no discurso de inauguração, traçou o destino deste espaço:

“Este Museu - biblioteca tem de ser por força da imperativa vontade do doador, aquilo, que, afinal, todos os Museus deviam ser - casas de ativa educação, colaborando, particularmente, na formação do gosto e do carácter. Estão já longe os tempos em que os Museus nada mais eram do que sumptuosas arrecadações de obras primas criadas 
pelos homens." (Couto,1931/ 1971, p. 13)

Aconselha a que o trabalho no museu se inspire no que de mais inovador se faz na América do Norte, visto que "a lição dos museus da Europa é, com raras excepções, antiquada (...)" (Couto, p. 13). Em contrapartida na América do Norte o:

"Museu (...) é escola viva, mas onde se prepara o renovamento do gosto pela arte, onde cada objeto de séculos idos é lição para o dia de amanhã." (...)"(Couto, p. 13).

A sua concepção de museu abrangente, e onde a criatividade não deve ser descurada, é-nos igualmente veiculada neste primeiro discurso público, que subentende toda uma reflexão a nível das funções de uma instituição cultural. Não se coíbe nunca, e em vários escritos, de criticar quem apresentava uma 'estreiteza de vistas' pois, em sua opinião, "o Museu é o abrigo onde cabem todas as manifestações artísticas - das artes plásticas, à música e à coreografia. (...) Só nos pequenos cérebros cabe a ideia de que os Museus atrofiam as ideias e o génio criador" (Couto, p. 14).

A música, que considerava como sendo uma das artes que devem ser incluídas no museu e que, no caso em estudo, coincide com o gosto do seu antigo proprietário, torna-se uma prioridade logo no ano de abertura ao público, iniciando-se os concertos de órgão, todos os domingos, "sem programa nem anúncio" (Couto, Jornal de Cascais, 1931e, 20 janeiro). Nas duas primeiras sessões a presença da população foi escassa, mas a partir daí tornou-se mais numerosa e interessada, vindo até da Capital, fazendo jus ao entusiasmo persistente do conservador que sempre terá defendido que o alargamento de públicos não se deve limitar, apenas, a "circunspectas pessoas que segurando o metro e a lupa, percorrem as salas acolhedoras a indagar de complexos problemas", (Couto, 1931/1971, p. 13) mas se alarga "à 
população alegre das escolas, de todas as idades e de todos os graus" (p.13), aos "operários de todos os ofícios" (p.13), às pessoas de todos os grupos sociais:

"que sorvem, através das sóbrias indicações de diligentes conservadores - mestres, essa formosa lição de beleza pela arte, que os Museus não devem sepultar, mas reviver constantemente para satisfação dos nossos ávidos sentidos. [...]" (Couto, 1931/1971, p. 14).

A dança rítmica que, na perspetiva de João Couto, era essencial para a formação holística do indivíduo, vai ser por si defendida em numerosos artigos, sobretudo, de âmbito escolar. Neste escritos fez propostas concretas para a reestruturação dos currículos onde esta atividade devia ser incluída, a par da Educação Física, da História da Arte e do Canto Coral. No Museu-Biblioteca passa da teoria à prática e, desde muito cedo, a dança rítmica é parte integrante da programação das atividades. Logo em 1932, a 24 de Julho, Sosso Doukas (Madame Schau) realiza, com as suas alunas, um espetáculo de dança rítmica na 'Fonte' do parque do Museu - Biblioteca.

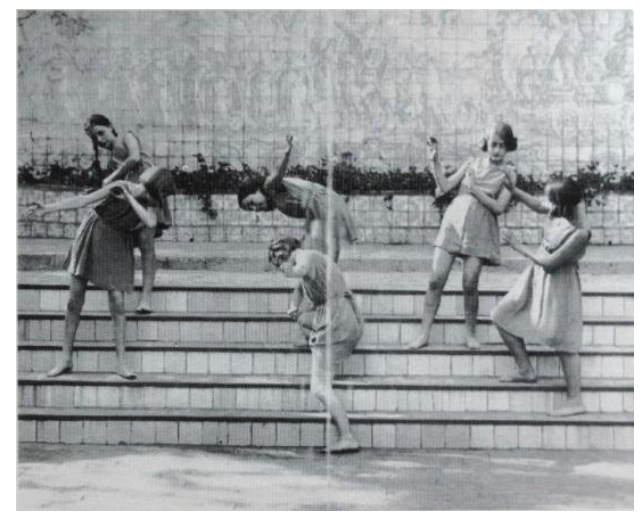

Figura 2 Espetáculo de dança rítmica na 'Fonte' do parque - 1932 
Fonte: Schau, 2011, p.31

Pretendeu, igualmente, este último investir na história local, quando se propôs organizar uma sala dedicada a Cascais, mas para a qual reconheceu ter muito pouco acervo, como se comprova através de uma carta datada de 1-5-1931, endereçada ao Presidente da Câmara:

"É minha intenção organizar neste museu uma pequena sala onde se juntem todos os documentos que interessem à vila e história de Cascais, depois, possivelmente, ao seu Concelho. Com este objetivo estou mesmo já reunindo elementos, aliás difíceis de obter" (Couto, AHMC, 1931a).

Possuímos, assim, um museu que se pretende dinâmico, ao serviço da educação e da população, e com uma preocupação de ligação com a história / identidade e comunidade local, que conduz o seu Conservador, a partir de Outubro de 1931, a criar uma nova sala de leitura no rés do chão "por virtude da afluência de leitores e comodidade destes" (Couto, AHMC, 1931c) e, desde os finais de Novembro do mesmo ano, a abrir a biblioteca do museu às $2^{\text {as }}$ e $6^{\text {as }}$ feiras das 21 às 23.30h, ficando "assim atendidos os pedidos de muitas pessoas de Cascais [...]" (Couto, AHMC, 1931d).

Os inovadores conhecimentos, que adquire na bibliografia internacional, são aplicados no Museu de Cascais, como podemos verificar em toda a atividade desenvolvida, e têm reconhecimento público. A proteção patrimonial está sempre associada à divulgação do espaço e da obra, com uma dinâmica e pioneirismo invejável, visto que se fazem "palestras e conferências ilustradas por projecções" podendo o espaço "ser hoje tido como um centro de apreciável cultura, num país onde todas as obras desta natureza tão pouco 
estimadas e acarinhadas, não têm logrado a nomeada que este vai tendo" (Couto, AHMC, 1931b).

A intensa atividade cultural vai ser uma constante, sendo os concertos, conferências e congressos complementados com cursos de férias desde 1934 organizados pela Faculdade de Letras da Universidade de Lisboa -, iniciando uma ligação ao meio académico que ainda hoje perdura, sessões públicas de leitura, publicações, algumas das quais começaram logo no ano de abertura e que estavam diretamente relacionadas ou com as preocupações / missão do museu, ou com a história local. Merecem, também, destaque os Cursos Musicais Internacionais de Férias, organizados pela Junta de Turismo do Estoril desde 1962, hoje integrados nas semanas de Música do Estoril.

As publicações foram outra das preocupações e, em 1940, no ano dos Centenários, disponibilizam-se ao público três publicações sobre Cascais. Após a saída de João Couto, é selecionado, após concurso, Carlos Bonvalot, convidado mais tarde para dirigir a oficina de restauro do Museu Nacional de Arte Antiga.

Acrescente-se que, em 30-8-1939 - dia de feriado concelhio -, no tempo em que João de Lacerda foi nomeado delegado da Comissão Administrativa, foi aberta a 'Biblioteca Nova Popular e Infantil do Jardim Visconde da Luz', "na sua quase totalidade constituída por crianças pobres o que compensava largamente o Museu da despesa e esforço despendidos" (Ata no 62). Esta experiência, uniu esforços, quer por parte do Museu, quer por parte da Câmara.

\section{Conclusão}

Desde a génese deste Museu - Biblioteca que João Couto pretendeu uma articulação consciente com o meio envolvente, reconhecendo a museologia como um meio e forma de expressar a sua compreensão dos valores da memória e do património. O museu não era apenas um 
espaço expositivo, mas um espaço de dinamização cultural, um espaço de ação, concretizada por intermédio de uma grande diversidade patrimonial: do livro à música, passando pela arte, poesia, conto, dança... encarado não apenas do ponto de vista da herança e da incumbência pela sua preservação, mas, sobretudo, destacando a transmissão e a comunicação onde o património mais valorizado são as pessoas. O usufrutuário deste processo comunicacional educativo não é considerado acrítico, passivo, indiferente, alheio e apático, mas um ser que age, interage, na relação que estabelece com a instituição, no seu território de intervenção. $O$ utilizador pode escolher a forma como comunga deste espaço, pela seleção dos 'pedaços patrimoniais' que medeiam o processo de comunicação e que vão determinar as distintas maneiras de apropriação e reapropriação de um património, que irrigará a sua relação com o local, conduzindo à valorização do sentido de pertença e à (re)construção e revalorização da(s) sua(s) identidade(s). 0 espaço e as coleções deste museu foram valorizadas, protegidas, divulgadas, comunicadas a toda a comunidade através da ação educativa que foi, desde o início da sua existência, variada e multifacetada, tentando abranger uma pluralidade de públicos. O objetivo, de quem o dirigia, era que a comunidade permanecesse no museu e não que viesse apenas visitar o museu. A tónica prende-se com o facto da ação educativa mediar a abertura do museu à comunidade, isto é, a ação educativa era uma preocupação transversal a toda a instituição, pelo vanguardismo e pioneirismo de João Couto. Defendeu intransigentemente a educação pela arte no sentido lato - para a formação completa do indivíduo. Esta função pedagógica deveria servir a todos, independentemente da idade e da situação socioeconómica e cultural. O pioneirismo, que aqui inculca, advém da sua formação no seio de simpatizantes do republicanismo e de toda uma corrente inovadora da museologia que chegava da 
América do Norte.

\section{Referências Bibliográficas}

10 Livro de Atas da Comissão Administrativa do Museu - Biblioteca Condes de Castro de Guimarães, 1931 - 1945: Ata $\mathrm{n}$ - 62 de 30 - 9- 1939

Bardin, L. (1988). Análise de Conteúdo. Lisboa: Eds. 70 (ed. França1977 - PUF).

Chagas, M. de S. (2003). Imaginação Museal: Museu, Memória e Poder em Gustavo Barroso, Gilberto Freire e Darcy Ribeiro, Retirado a 3 janeiro, de 2012, em

scribd.com/doc/50087891/Imaginacao-MusealMuseu-Memoria-e-Poder em Gustavo-Barroso-GilbertoFreyre-e-Darcy-Ribeiro - Chagas -Mario (consultado em janeiro 2012). publicado em 2009, Rio de Janeiro, Ministério da Cultura / IBRAM

Couto, J. (1931a). Carta ao Presidente da Câmara de Cascais. Manuscrito não publicado, AHMC, A1 RA/002 193047 Cx1 1-5-1931.

Couto, J. (1931b). Carta ao Presidente da Comissão Administrativa do Museu - Biblioteca Condes de Castro Guimarães. Manuscrito não publicado, AHMC, A1

RA/002 1930-47 Cx1, 19-7-1931, p.1 e 2.

Couto, J. (1931c). Carta ao Presidente da Comissão Administrativa do Museu - Biblioteca Condes de Castro Guimarães. Manuscrito não publicado, AHMC, A1 RA/002 1930-47 Cx1, 17-10-1931.

Couto, J. (1931d). Carta ao Presidente da Comissão Administrativa do Museu - Biblioteca Condes de Castro Guimarães. Manuscrito não publicado, AHMC, A1

RA/002 1930-47 Cx1, 23-10-1931.

Couto, J. (1931/ 1971). Discurso de Abertura do Museu (discurso pronunciado na inauguração do museu em 1931). Boletim do Museu-Biblioteca Condes de Castro Guimarães, no 
2. Cascais: Câmara Municipal de Cascais, pp. 9-15.

Couto, J. (1931e, 20 janeiro) Jornal de Cascais, no 4.

Couto, J. (1932). A Escola sem Arte. Boletim do Liceu

Normal de Lisboa (Pedro Nunes), no 3, Lisboa: pp. 312-329.

Couto, J. (1961, julho). O Ensino e a Arte. Palestra, no12. Lisboa: pp.11-18.

Couto, J. (1965, janeiro a março). Curso de Museologia a estagiários para conservadores dos Museus, Palácios e Monumentos Nacionais, 18a lição. Separata da Ocidente, vol. LXVIII, no 321, Lisboa

Fortin, M. F. (1996/2003). O Processo de Investigação: da concepção à realização. 3ạ ed. Lisboa: Lusociência.

Ketele, J. M., \& Roegiers, X. (1999). Metodologia da Recolha de Dados. Lisboa: Instituto Piaget.

Schau, P. (2011). Sosso Doukas - Schau - Uma vida ao serviço da dança rítmica. Lisboa: ed. de autor. 